\title{
Service Learning and Simulations
}

Shannon Jenkins, University of Massachusetts, Dartmouth

\author{
ABSTRACT Both service learning and simulations have been shown to positively impact \\ student outcomes, but they are not often used together. This article examines how to effec- \\ tively combine these active learning styles to reap the benefits of both. After examining a \\ case in which the two were combined and the impact this approach had on student eval- \\ uations and learning outcomes, I discuss how such projects can be successfully executed in \\ a variety of other classes.
}

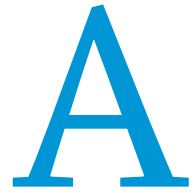

mple evidence demonstrates that active learning techniques such as service learning and simulations are a proven way to increase student learning and engagement. However, these methods are often used in isolation, with no real connection drawn between them. Exposing students to multiple ways of learning can only help increase their knowledge of and interest in a subject matter, so it is worthwhile to explore how to effectively combine different types of active learning techniques to reap the benefits of each. In this article, I examine how to successfully pair service learning projects with simulations and incorporate such pairings into other classes.

\section{THE BENEFITS OF ACTIVE LEARNING TECHNIQUES}

The benefits of service learning are well documented. Service learning has a positive impact on student personal outcomes such as personal efficacy, moral development, and the ability to work with others; social outcomes such as facilitating racial and cultural understanding, citizenship skills, and continued community involvement; and student relations with their institution of higher learning such as stronger ties with faculty and increased likelihood of graduation (Eyler et al. 2001). In the classroom, participation in service learning projects has been found to have positive impacts on grade point averages, critical thinking skills, writing skills, understanding of the political process, beliefs about the importance of politics, issue identification skills, and political participation skills that are over and above any benefits that stem from engagement in service alone (Astin et al. 2000; Eyler and Giles 1997; Eyler, Giles, and Braxton 1997; Giles and Eyler 1994).

Simulation projects have also demonstrated many benefits similar to those stemming from service learning projects. With respect to cognitive learning outcomes, studies have documented that simulations lead to increased understanding of lectures and course materials and increased capacity to understand complex situations (Frederking 2005; Grummel 2003; Lay and Smarick 2007; Pappas and Peaden 2004; Shellman and Turan 2006). Because students are forced to apply theories and concepts to lifelike situations, they gain a deeper understanding of those materials, as

Shannon Jenkins is an assistant professor of political science. She teaches courses on state politics, public policy, and research methods. Her research focuses on state legislatures as well as the impact of high-impact educational practices on student outcomes. She can be reached at sjenkins@umassd.edu. well as the ability to analyze and think critically about the information they have received in class (Shellman and Turan 2006).

In addition, simulations positively influence student evaluations of a class and their experiences. Simulations increase motivation to learn, create an increased sense of responsibility for learning (Jacobs, Power, and Inn 2002), and positively impact student perceptions of the course and their overall learning experience (Caruson 2005; Galatas 2006; Kathlene and Choate 1999).

Given the amount of evidence that suggests that both of these learning strategies have benefits in the classroom, it seems that a combination of the two would be beneficial for students, given that they both enhance the learning experience in a variety of ways and may complement each other. Thus, it is worth thinking about how to use them together in a positive manner. The following sections offer an example of how this combination can be made.

\section{SERVICE LEARNING AND SIMULATION IN MASSACHUSETTS POLITICS}

"Massachusetts Politics" is an upper-level political science class that examines the politics and policies of the commonwealth of Massachusetts. One of my key objectives for this course is for students to think about the many problems the state faces (e.g., declining population, high housing costs, burgeoning health care and pension costs) and how we might solve these problems. Often, students come to class with the idea that government is an obstacle to solving problems in the state, or that government ought to be doing more but chooses not to. My goal is to foster the understanding that many of these problems are complex and there is much disagreement about how to fix them, making it difficult for government to act. Both the service learning and simulation projects are designed to help achieve this goal.

\section{Service Learning}

Classroom lectures, discussions, and group activities are primarily designed to inform students about state government, processes, actors, and policy. To give students firsthand and in-depth knowledge about some of the problems in the state, I require them to complete 15 hours of public service. I offer a number of prearranged service opportunities, but students are also allowed to select their own placement, subject to my approval. Students must notify me of their selection prior to the commencement of their service. Over two offerings of this class, students have selected a 
variety of organizations to work with, including but not limited to an animal shelter, a nursing home, local arts organizations, various educational programs, and a public library. Because of the large number of placement sites, I do not visit each student on site. Rather, I ask their supervisors to monitor their time worked, and students are required to keep a timesheet, signed by their supervisor each time they work.

In addition, students are required to keep a journal of their experience. Over the course of the semester, as we discuss a variety of public policy areas, I often ask students to draw on their specific service experiences to deepen our discussion. For example, when we talk about educational policy, I direct specific questions related to the service learning experience to students tutoring at a local elementary school. Students must also interview their supervisor, focusing on how state government impacts the work of the agency and how state government might act (or reduce its actions) to facilitate the work of the agency. Students must complete their service hours and submit the required materials before the start of the simulation, which occurs during the last two weeks of class. As research has shown that reflection is critical to the effective functioning of service learning projects, I have designed requirements that tie reflection in with the simulation, which are discussed in the following sections.

\section{Simulation}

At the end of the semester, students participate in a two-week legislative simulation. In this simulation, the class acts as the Massachusetts Senate and engages in lawmaking. This exercise is the outdoors. Another student who worked in an organization providing services for children with autism proposed bills to increase funding for early testing of children exhibiting signs of autism and to increase support services in schools for such children.

After a one-day introduction and preliminary session in which students organize themselves into party caucuses and select party leaders, students break into committees to consider the various bills that have been proposed. Students have complete control over how to organize these committees and assign bills. In the committees, students then debate and discuss the legislation; for bills that are similar, there is the option of merging the two. Students may also change these bills as they see fit. Finally, they must vote as a committee on whether or not to approve the bill. Students have had over 100 bills to consider in each offering of this course, so there is always much debate in the committees. Almost every student participates in this dialogue, either to promote his or her own bills or discuss the merits of bills proposed by others. The result is deep discussion about the way to tackle important (and not so important) problems.

Next, students are given a day to debate the bills, which is their chance to persuade their colleagues to support and prioritize their proposed legislation. At the end of this session, the party leaders turn in a list of the bills that have passed out of committee along with an indication of the order in which the bills will be considered. Finally, the last session of the simulation is the floor session, when students vote on the legislation. Students can choose to allow debate and amendments or not. In prior situations, they

\section{Students commonly express the opinion during the semester that government spending is wasteful or extravagant, but during the simulation, they engage in the same sort of behavior they criticize. This experience helps them realize the difficulty of representing constituent and personal demands for services while simultaneously looking out for the greater good and keeping spending in check.}

culmination of the course and is designed to tie together information from class readings, lectures, discussion, and the various service learning projects. Each student selects a senatorial district to represent in the simulation. Before the simulation begins, each student submits a report on his or her district that focuses on its demographic, physical, economic, and political characteristics. Students are also asked to speculate on what they perceive as the top policy concerns of their district. The goal of this assignment is to force students to think about the interests they will be representing in the simulation.

Students are also required to submit at least four bills for Senate consideration. They may submit additional bills for extra credit, and they also receive extra credit based on how far their bills progress through the legislative process. Crafting bills is one area in which I encourage students to reflect on their service learning project, because their experiences provide them with special expertise in understanding certain problems in the state, much like the expertise that comes from legislators' committee assignments. For example, a student who served in an animal shelter proposed bills to require people to spay or neuter their pets and keep their dogs leashed or contained while have chosen to allow both. Consequently, my students have never voted on all of the bills that make it out of committee, because over 60 bills in each course section have been approved by the committees. This is not a bad thing, as I remind them that real legislatures are often unable to consider all proposed bills in a legislative session.

Finally, we spend a day reflecting on the simulation, the service learning projects, and the course as a whole. I first provide students the opportunity to air grievances, and some get in heated exchanges about specific issues, the treatment of their bills, and similar topics. This dialogue is productive in that it allows me to discuss the difficulties of working with people with whom you vehemently disagree. In an abstract sense, it can be hard for students to understand why partisanship plays such a large role in politics, but after two short weeks of trying to forge agreement on weighty issues, they begin to understand the challenges of working on a day-to-day basis with someone with whom you strongly disagree.

Next, we talk about the tendency to pass bills that require new spending. Students commonly express the opinion during the semester that government spending is wasteful or extrava- 
gant, but during the simulation, they engage in the same sort of behavior they criticize. This experience helps them realize the difficulty of representing constituent and personal demands for services while simultaneously looking out for the greater good and keeping spending in check. We also spend some time talking about the bills themselves, discussing what passed and what did not. The bills students propose are obviously not as detailed as the bills that the real Senate would consider, but students have trouble coming to agreement even on this oversimplified legislation. Many express disappointment if their bills do not pass, not only because they want extra credit, but also because they have proposed a "good" or "important" bill. We discuss issues that were covered in class but were not a subject of any of the legislation. Often, students say that these issues were too complex for them to tackle in the simulation. Both of these points relate to one of my overarching themes that solving many state problems is a difficult and complicated endeavor. In this discussion, we also spend some time talking about students' service learning experiences and their connection to the simulation and the class generally. Many students express frustration that bills related to their service learning experience, which they now see as very important, did not receive full consideration. For example, neither of the animal-related bills mentioned previously were voted on, even though they passed out of committee. These exclusions help students realize the vast array of issues facing state government, and that, often, nonprofit agencies have great difficulty in getting the state legislature to pay attention to them. Students see that what they originally perceived as state neglect is in fact state overload. In sum, the simulation discussion session serves to tie their active learning experiences to both more abstract themes covered earlier in class and key learning objectives.

After the simulation, students are required to write a final "state of the state" address to their constituents. They are asked to talk about what is good in the state and what has been accomplished in the latest legislative session along with what is wrong and still needs to be done. I ask students to draw on course readings and discussions, the simulation, and their service learning experiences in writing this paper. Again, this assignment serves as a means to debrief students on both the service learning and simulation projects. Generally speaking, I have been very impressed with the quality of these papers. For example, one of my more conservative students described in his speech his experience volunteering in a poor school district and proposed that we dedicate a certain portion of state lottery revenue and cigarette taxes to these schools, since much of the money the state receives in these areas come from poor dis-

Table 1

\section{Responses to Affective Questions about the Political System}

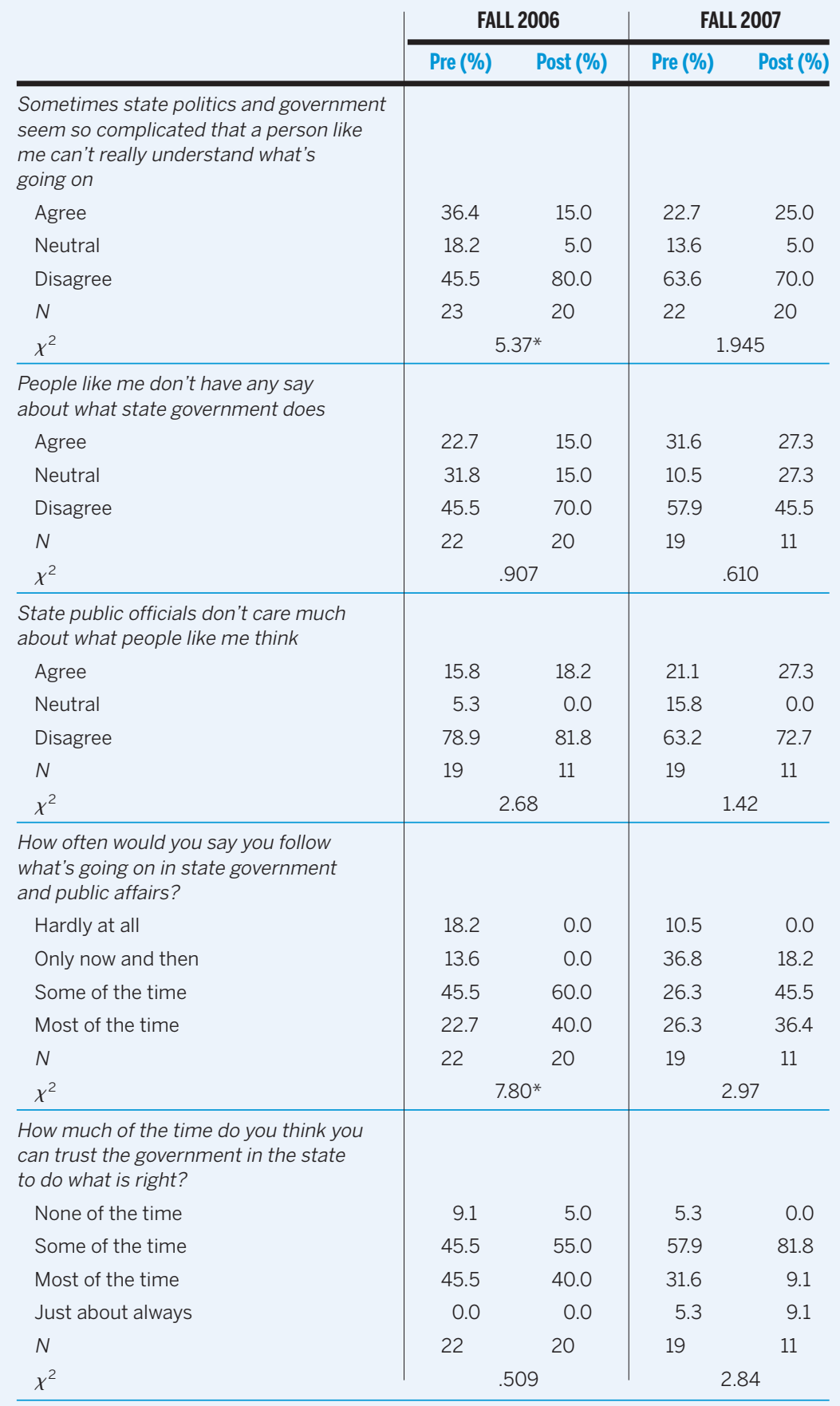

Note: ${ }^{* *} p<.01,{ }^{* *} p<.05,{ }^{*} p<.10$ tricts. Another student discussed his work with the United Way in soliciting volunteer opportunities for their Web site and proposed a bill to provide state support for more service learning courses. Overall, these papers indicate that both the service learning and simulation experiences can help foster a better understanding of the complexities of dealing with state problems. 


\section{IMPACT ON STUDENT}

\section{LEARNING AND}

\section{ENGAGEMENT}

Impressionistic accounts suggest that the service learning and simulation projects had a positive impact on student learning and engagement. However, student course evaluations and survey responses show more systematically that these activities positively impacted learning and engagement. First, student evaluations of the course were very favorable. On all measures of the department's standard evaluation instrument assessing opinions about items such as consideration of different points of view and encouragement of classroom participation, student evaluations were higher than the department average and fell closest to the most optimal response.

Students' open-ended comments were positive as well. One student noted that "every Massachusetts resident should learn about the material covered in this course." Comments also reflected the connection between the projects and my learning objectives. One student noted, "The service-learning project really made me aware of some of the issues that are going on in our state." Another said, "The legislative simulation really illuminated a lot of the theoretical aspects of the course." Others noted the difficulty of accomplishing policy goals. Numerous students mentioned the simulation, with 11 out of 32 (across two semesters) mentioning it positively in the open-ended comments. Service learning was mentioned less frequently; four students referenced it positively in fall 2006, while none did in 2007. One negative comment was made in each semester about the number of required service hours.

In addition to student course evaluations, I administered a survey designed to assess students' knowledge about state politics and their affect toward the political system. The survey was administered during the first week of class as well as at the end of the semester. This instrument used standard measures designed to assess feelings about the political system; the wording of the questions was adapted from the National Election Study, replacing national government indicators with state government indicators. As table 1 shows, for all questions and in both sections of the course, students felt more positively toward the political system at the end of the course than they did at the beginning. Only a few of these differences are statistically significant, which may partially be due to the small number of respondents. In fall 2006, students were significantly more likely to say they followed state politics more frequently and less likely to say that state politics were too complicated for someone like them to understand.

As table 2 shows, student knowledge was positively impacted as well. For every item and in both sections, more students responded correctly to questions about various aspects of state politics at the end of the semester than did students at the beginning. Most of these differences are statistically significant. For the question on the governor's council, neither section's differences were significant; in fact, this was the question that students most frequently got wrong. All other items demonstrated a significant improvement in student learning.

Of course, it would be ideal to have a section of the course that includes no service learning or simulation requirements for comparison purposes. Unfortunately, in a small department, no other faculty offers this course without these components, nor is there a readily comparable class in which to administer this survey. With this limitation in mind, the data suggest that student learning and affective outcomes were positively impacted in this class. Taken in conjunction with student comments about the course, I would argue that the service learning and simulation projects played an important role in creating this effect.

\section{DISCUSSION}

In this situation, a service learning project was effectively combined with a simulation with positive results. Of course, no project is perfect, and there is always room for improvement. My key concern for future offerings relates to the service learning project. Although there are some benefits to having students select a variety of projects that help them gain different expertise on which to draw in the simulation, this approach made it more difficult to effectively integrate the service learning experiences into the class early in the semester. I was able to draw on the experiences of some students during class discussions and debrief sessions, but not all were included. In the future, I will explore offering students a choice of three or four prearranged service projects. This method will allow me to visit service sites, more closely monitor the service work, and better integrate these experiences earlier in the class. I can also arrange students into committees based on their service experiences and give them time earlier in the semester to write bills jointly.

However, despite some limitations, this project was quite successful and could clearly be applied to similar political science classes, such as state politics, local politics, public policy, or American politics. For instance, such a combination could be used in a public administration course. Students could complete service projects in local government and nonprofit organizations and then simulate an organizational response to a local crisis that would require an increased demand for local services. As an example, immigration officials recently raided a factory in a nearby community; local government and community organizations were 
forced to respond with a wide array of services, including legal aid, housing for displaced families, and food and shelter for other workers who lost their jobs at the factory. In such a class, students could be asked how their organization would work with other agencies (also simulated by students) to formulate a response to this or a similar crisis or disaster.

In addition, instead of having students craft bills, instructors could create bills and have students act as legislators or assume a variety of different roles to consider in recommending a policy. For example, a policy class that looks at poverty might require students to volunteer with a variety of agencies dealing with that issue. For the simulation, students might act as a presidential advisory committee on poverty and choose an approach from several alternatives to recommend to the president. Politicians often call on experts from a wide variety of fields to help in crafting policy solutions; there is no reason why students from a variety of classes could not also simulate such experiences.

Given the widely documented benefits of both service learning and simulation techniques, creative thinking about how to combine these types of projects for maximum benefit would help both students and faculty. Of course, such combinations need to be carefully crafted to ensure that each directs students toward clear learning goals. When done properly, however, combining service learning and simulation activities is a rewarding experience for both students and faculty.

\section{NOTE}

I would like to thank Alan Holiman for the inspiration for this project, Deirdre Healey for her support, and Doug Roscoe for his comments on the manuscript.

\section{REFEREN CES}

Astin, Alexander W., Lori J. Vogelgesang, Elaine K. Ikeda, and Jennifer A. Yee. 200o. "How Service Learning Affects Students." http://www.gseis.ucla.edu/heri/ PDFs/HSLAS/HSLAS.PDF.
Caruson, Kiki. 2005. "So, You Want to Run for Elected Office? How to Engage Students in the Campaign Process Without Leaving the Classroom." PS: Political Science and Politics 38: 305-10.

Eyler, Janet, and Dwight Giles, Jr. 1997. "The Importance of Program Quality in Service-Learning." In Service-Learning: Applications from Research, ed. Alan S. Waterman, 57-66. Mahwah, NJ: Erlbaum.

Eyler, Janet, Dwight E. Giles, Jr., and John Braxton. 1997. “The Impact of ServiceLearning on College Students." Michigan Journal of Community Service Learning 4: $5^{-15}$.

Eyler, Janet S., Dwight E. Giles, Jr., Christine M. Stenson, and Charlene J. Gray. 2001. "At A Glance: What We Know About the Effects of Service-Learning on College Students, Faculty, Institutions and Communities, 1993-200o." 3rd ed. http://www.servicelearning.org/filemanager/download/4192_AtAGlance.pdf.

Frederking, Brian. 2005. "Simulations and Student Learning." Journal of Political Science Education 1: 385-93.

Galatas, Steven E. 2006. "A Simulation of the Council of the European Union: Assessment of the Impact on Student Learning." PS: Political Science and Politics 39: 147-51.

Giles, Dwight E., and Janet Eyler. 1994. "The Impact of a College Community Service Laboratory on Students' Personal, Social, and Cognitive Outcomes." Journal of Adolescence 17: 327-39.

Grummel, John A. 2003. "Using Simulations to Teach Decision-Making within the Policy Process." PS: Political Science and Politics 36: 787-89.

Jacobs, George M., Michael A. Power, and Loh Wan Inn. 2002. The Teacher's Sourcebook for Cooperative Learning. Thousand Oaks, CA: Corwin.

Kathlene, Lyn, and Judd Choate. 1999. "Running for Elect Office: A Ten-Week Political Campaign Simulation for Upper-Division Courses.” PS: Political Science and Politics 32: 69-76.

Lay, J. Celeste, and Kathleen J. Smarick. 2007. "Simulating a Senate Office: The Impact on Student Knowledge and Attitudes." Journal of Political Science Education 2: $131-46$

Pappas, Christine, and Charles Peaden. 2004. "Running for Your Grade: A SixWeek Senatorial Campaign Simulation.” PS: Political Science and Politics 37: 859-63.

Shellman, Stephen M., and Kursad Turan. 2006. "Do Simulations Enhance Student Learning? An Empirical Evaluation of an IR Simulation." Journal of Political Science Education 2: 219-32. 


\section{Advancing Political Science ..}

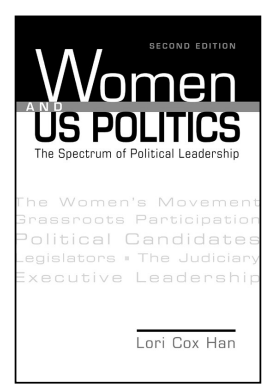

NEW-2ND EDITION!

Women and US Politics:

The Spectrum of

Political Leadership

LoRI COX HAN

"At last, a text designed to complement how many of us in the field actually teach women and politics."

-Ann Gordon, Chapman University pb $\$ 26.50$

\section{Hillary Clinton's Race for the White}

House: Gender Politics and the

Media on the Campaign Trail

Regina G. Lawrence \& Melody Rose

"Excellent.... Anyone interested in [US] politics, presidential campaigns, media politics, and the role of gender in American elections should devour this book."

-Library Journal • hc \$65 • pb \$26.50

\section{Presidential Elections in the South:} Putting 2008 in Political Context

Branwell DuBose Kapeluck, Robert P. Steed \& Laurence W. Moreland, editors

"Indispensable.... Provides invaluable insights into the future of politics in the American

South."-Stephen D. Shaffer,

Mississippi State University • hc \$65

\section{The Arab Gulf States:}

Beyond Oil and Islam

SeAn Foley

"This engaging study of the political, social, and cultural dynamics of the Arab Gulf states demonstrates that popular images do not reflect the much more complex reality."-Agnieszka Paczynska, George Mason University • hc \$69.95 • pb \$26.50

\section{Africa: Unity, Sovereignty, and Sorrow Pierre Englebert \\ "Powerful... This is an impressive and compelling book."-Patrick Chabal, International Affairs • hc \$65 - pb \$26.50}

New-2nd edition!

Doing Comparative Politics:

An Introduction to

Approaches and Issues

TıмотнY C. LIM

"Superbly demonstrates how comparativists use theory to grapple with important questions.... [An] engaging and well-structured text." -Laura Luehrmann, Wright State University • pb $\$ 27.50$

The Power Curse: Influence and Illusion in World Politics

Giulio M. Gallarotti

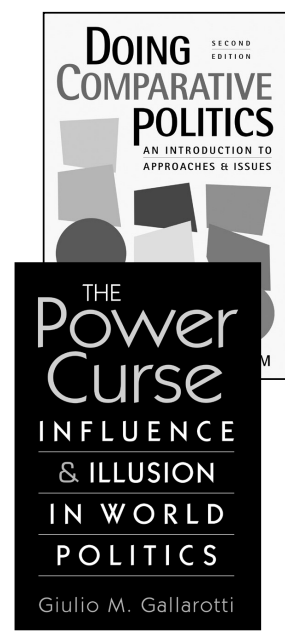

"Gallarotti uses diverse threads to weave a powerful and important tapestry of the ways in which the unwise but common use of power can backfire.”-Robert Jervis, Columbia University • hc $\$ 58.50 \cdot$ pb $\$ 22$

\section{Latin America's Left Turns: \\ Politics, Policies, and Trajectories of Change}

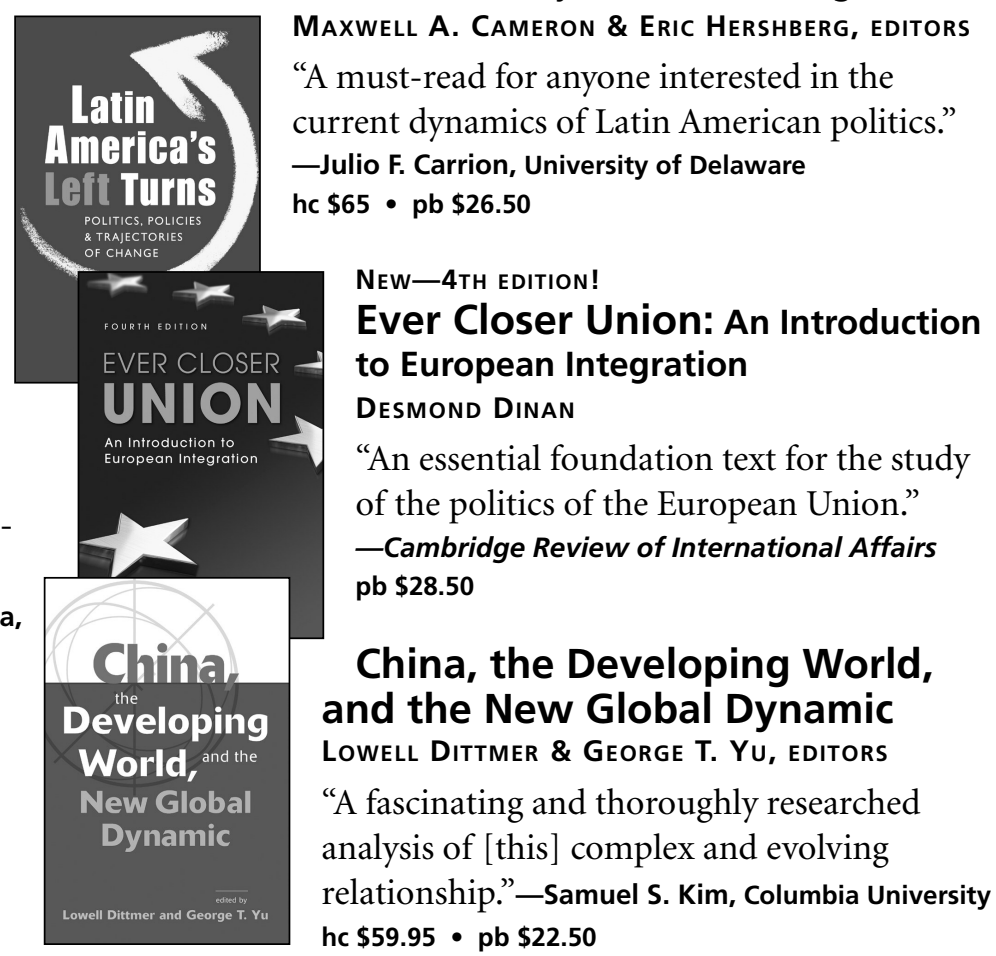

